\title{
A Novel Joint Index Based on Peripheral Blood CD4+/CD8+ T Cell Ratio, Albumin Level, and Monocyte Count to Determine the Severity of Major Depressive Disorder
}

\section{Dechun Zhou}

Ciwu Town community Health Service Center of Zhuji

Hongfeng Yu

Zhuji People's Hospital

Hongfeng Yao

Zhuji People's Hospital

Shijin Yuan

Zhejiang University

\section{Yan Xia}

Zhejiang University

\section{Lei Huang}

Sir Run Run Shaw Hospital

\section{Yuedi Shen}

School of Medicine,Hangzhou Normal University,

Jun Zhang

Sir Run Run Shaw Hospital

Wei Chen ( $\nabla$ srrcw@zju.edu.cn )

Sir Run Run Shaw Hospital

\section{Research Article}

Keywords: Major depressive disorder, Peripheral blood laboratory investigation, Biomarker, Joint index

Posted Date: September 16th, 2021

DOl: https://doi.org/10.21203/rs.3.rs-820901/v1

License: (1) This work is licensed under a Creative Commons Attribution 4.0 International License. Read Full License 
Version of Record: A version of this preprint was published at BMC Psychiatry on April 8th, 2022. See the published version at https://doi.org/10.1186/s12888-022-03911-5. 


\section{Abstract}

Background: A peripheral blood laboratory test may be an easy and ideal method for determining major depressive disorder (MDD) severity, because the current depression assessment scales lack sensitivity and objectivity. This study was aimed at exploring the association between laboratory parameters and disease severity.

Methods: MDD severity in the training and validation cohorts ( $n=99$ and 97, respectively) was classified using the Hamilton Depression Scale. Pretreatment laboratory parameters were evaluated. Significant severity-associated factors were identified using a multivariate logistic model and combined to develop a joint index through binary logistic regression analysis. The area under the receiver operating characteristic curve (AUC) was used to evaluate the index's discriminative performance.

Results: In the training cohort, lower CD4+/CD8+ T cell ratio, albumin level, and a higher monocyte percentage $(\mathrm{M} \%)$ were significantly associated with severe disease $(\mathrm{P}<0.05$ for all). The index was developed using these factors and calculated as -3.959 CD4+/CD8+ T cell ratio -0.175 albumin level + $0.522 \mathrm{M} \%+8.739$, with a sensitivity and specificity of $90 \%$ and $70 \%$, respectively. The AUC values for the index in the training and validation cohorts were 0.850 and 0.750 , respectively, indicating a good discriminative performance.

Conclusion: We identified disease severity-associated laboratory parameters that could be easily evaluated-CD4+/CD8+ $T$ cell ratio, albumin level, and $M \%$-and developed and validated a joint index for discriminating MDD severity.

\section{Introduction}

Depression is a common mental disorder belonging to a group diseases attributable to various causes, It is characterized by a considerable lasting low mood or emotion change that is often accompanied by corresponding cognitive and behavioral changes, which can lead to several mental symptoms such as hallucinations, delusions, and even suicidal behavior. Major depressive disorder (MDD) is the most common subtype of depression disorder. The incidence of MDD is increasing rapidly, furthermore, it is a major health problem and a huge economic burden. The lifetime prevalence of MDD is estimated to be between $2 \%$ and $20 \%$, higher than that of other non-communicable diseases $[1,2]$. Moreover, MDD is one of the leading causes of disability worldwide [3], and an estimated 800,000 affected people by suicide annually [4].

The etiology and pathogenesis of MDD are complicated and have not been fully elucidated. At present, researchers consider the etiology of MDD to be multifactorial, and could be related to genetic, environmental, biological, physiological, psychological and social factors [5]. Among these factors, inflammatory processes and dysregulation of both the innate and adaptive immune systems are two widely investigated factors that have been considered to be closely related to the pathogenesis of MDD [6]. In the terms of clinical characteristics, patients with MDD may experience a marked and persistent 
depressive and pessimistic mood and loss of interest and enjoyment. These symptoms could be accompanied by somnipathy, eating disorders, and other symptoms associated with autonomic nervous dysfunction, Furthermore, patients with severe disease may have a strong suicidal tendency [7]. Previous studies showed that patients with MDD were more likely to attempt suicide during the first major depressive episode [8]. According to data from the United States data for 2018, suicide was the 10th leading causes of death, and approximately $60 \%$ of suicide cases were reported in patients with MDD [9].

Hence, early diagnosis of depression and prediction of its severity are key to facilitating the clinical diagnosis and optimizing treatment for patients with MDD, which could effectively reduce the suicide rate associated with depression. In daily clinical practice, two mood screening scales-the Hamilton Depression Scale (HAMD) and Montgomery-Asberg Depression Rating Scale (MADRS)-are the most easily understood and commonly used tools for the evaluation of a depressive status and treatment response $[10,11]$. However, these scales are used by investigators by observing patients and communicating with them, which may lend subjectivity to the assessment and result in some degree of bias. Besides, a previous study showed that the assessment reliability of HAMD is inadequate, owing to the poor contribution of several scale items to the measurement of depression severity [12]. Furthermore, the effectiveness of HAMD and MADRS in discriminating the severity of depressin remains disputable. Müller et al. [13] showed that MADRS was better than HAMD in terms of discriminating the severity of MDD. On the other hand, Carneiro et al. [14] determined that both scales had adequate reliability and validity for assessing the severity of MDD. Other researchers have used neuroimaging to estimate the clinical changes related to depression [15-18]. Nevertheless, the high costs and radiation damage associate with imaging techniques limited their application in this context. Hence, a sensitive and specific index that can be easily obtained from peripheral blood detection may be an ideal method.

Recent research has shown that the chronic low-grade inflammation and immune responses play important roles in the disease course of depressive disorder $[19,20]$. White blood cells (WBCs), neutrophils, monocytes, lymphocytes and subsets, platelets [21], C-reactive protein (CRP), and albumin can be easily determined from laboratory tests of peripheral blood, which could reflect the systemic inflammatory and immune status. Previous studies have shown that CRP level, mean platelet volume, and the levels of tumor necrosis factor (TNF)- $\alpha$ and cytokines such as interleukin- 1 and -6 , in peripheral blood were significantly higher in patients with depressive disorder than in a healthy population [22-25]. Moreover, the proportions of lymphocytes and their subsets significantly decreased in the patients with depressive disorder compared to that in a healthy population [26, 27]. In addition, Shen et al. [28] found that the level of interleukin-18 significantly decreased in patients with MDD who had an HAMD score lower than 7 than in patients with an HAMD score higher than 7 after fluoxetine treatment, This indicates that dynamic change in inflammatory cytokines may reflect the disease severity of MDD. Hence, this study was aimed at determing immune and inflammatory indicators that could be applied to evaluate the severity of depression and developing a novel detection model combining these multiple indicators to classify depression severity. 


\section{Methods And Materials}

\section{Participants and study design}

This retrospective study was conducted in the Department of Psychiatry, Sir Run Run Shaw Hospital, School of Medicine, Zhejiang University, approved by the ethics committee of the hospital and performed, according to the Declaration of Helsinki. Patients aged $\geq 18$ years and initially diagnosed with depressive disorder by experienced psychiatrists according to the criteria in the fifth edition of the Diagnostic and Statistical Manual of Mental Disorders (DSM-5) [29] were eligible for inclusion. The exclusion criteria were as follows: (1) a history of hypomanic or manic episodes, and a mood disorder questionnaire score of $<7$; (2) use of any antidepressants or other antipsychotic medications; (3) presence of comorbidities such as cancer, autoimmune disease, stroke, acute coronary syndrome, and infection; and (4) insufficient liver renal cardiac and bone marrow hematopoietic functions. From August 1, 2020 to December 31, 2020, eligible patients were enrolled into a training cohort. And from January 1, 2021 to April 30, 2021, eligible patients were enrolled into a validation cohort.

\section{Disease severity classification}

The 24-item HAMD was used to evaluate the status of depressive symptoms in patients through conversation and observation by two well-trained independent investigators. Patients with HAMD scores ranging from 8 to 20 and from 21 to 35 were classified as the mild and moderate depressive disorder groups; respectively,Further patients with HAMD scores of $>35$ were classified as the severe depressive disorder group. Patients with mild and moderate depressive disorder were considered the non-severe disease group, and those with severe depressive disorder were considered the severe disease group.

\section{Data collection}

Detailed clinical characteristics and laboratory test data were collected from the electronic medical record of each patient. Baseline laboratory data were collected within 1 week before treatment initiation, including WBC count, absolute neutrophil count (ANC), ANC as a percentage of the WBC count (N\%), absolute lymphocyte count (ALC), ALC as a percentage of the WBC count (L\%), absolute monocyte count $(A M C), A M C$ as a percentage of the WBC count (M\%), platelet count, and serum albumin, CRP and lactate dehydrogenase (LDH) levels. All fasting venous blood samples were collected in the morning and examined by laboratory physicians who were blinded to the clinical status of the study patients.

\section{Flow cytometry}

An 8-mL sample of peripheral blood sample treated with ethylene diamine tetraacetic acid (EDTA) was obtained from each patient at baseline for flow cytometric analysis. All tests were performed within 4 hours after sampling. To each tube was added $30 \mathrm{uL}$ of the whole blood sample and $10 \mathrm{uL}$ of antibodies against CD3, CD4, CD8, CD16, CD19 and CD56, The tube contents were mixed well and the tubes were incubated in a dark room with a temperature of $19-22^{\circ} \mathrm{C}$ for 20 minutes. Then, $200 \mathrm{uL}$ of erythrocyte lysate was added to each tube and mixed well, the tubes were then incubated in a dark room with a 
temperature of $19-22^{\circ} \mathrm{C}$ for 20 minutes. After that, $1000 \mathrm{uL}$ of normal saline and $30 \mathrm{uL}$ of Flow-Count Fluorospheres were added successively to each tube and incubated for 30 minutes. Fluorescence was analyzed by flowcytometry (Beckman Coulter, USA). The relative percentage and absolute count of each lymphocyte subsets, including CD $4+T$ cells, CD $8+T$ cells, CD16 + 56 + NK cells and CD19+ B cell were recorded. The investigators who performed flow cytometry were also blinded to the clinical status of the study patients.

\section{Statistical analysis}

Categorical variables were described as frequencies and percentages, The chi-square test was used to analyze significant differences. The Shapiro-Wilk method was used to test the normality of continuous variables. Continuous variables with normal distribution were described as mean and standard deviation (SD), Student's t-test was used to analyze significant differences. Continuous variables with a skewed distribution were described as median and interquartile ranges (IQRs), and the Mann-Whitney U test was used to analyze significant differences.

For the training cohort,a univariate logistic regression model was used to select the factors associated with disease severity $(P<0.05)$, These were incorporated into a multivariate logistic regression model to identify significant factors $(P<0.05)$ and calculate odds ratios (ORs) with $95 \%$ confidence intervals $(\mathrm{Cls})$. Based on independent significant factors, a novel joint index was developed via binary logistic regression analysis to distinguish disease severity. The best cut-off values of the joint index and single significant factors were determined using the maximum Youden index based on the receiver operating characteristic (ROC) curve, which was calculated as the sensitivity plus specificity minus 1 . The area under the curve (AUC) method was used to compare the diagnostic efficiency of the joint index and a single significant factor. In addition, the discriminatory performance of the joint index was tested in the validation cohort.

Statistical Product and Service Solutions version 22.0 and the R Programming Language version 3.6.0 were used to perform statistical analysis. All statistical tests were two-tailed and a $P$-value of $<0.05$ was considered statistically significant.

\section{Results}

\section{Demographics and laboratory investigations of patients}

From August 1, 2020 to December 31, 2020, 99 patients including 56 female patients (56.6\%), initially diagnosed as showing MDD were enrolled as the training cohort in this study. Among these, 36, 33, and 30 patients were classified as showing mild moderate MDD, and severe respectively. The median age of the patients was 32 years (IQR, 19-48, years). Detailed clinical characteristics and baseline laboratory investigations of the patients in the training cohort are provided in Table 1. 
Table 1

Baseline clinical characteristics and laboratory investigations of patients in the training and validation cohort

\section{All Patients $(\mathrm{N}=\quad$ Training Cohort $(\mathrm{N} \quad$ Validation Cohort $(\mathrm{N}$ 196) = 99) =97)}

\section{Clinical Characteristics}

Gender

Female

123 (62.8)

56 (56.6)

67 (69.1)

Male

73 (37.2)

43 (43.4)

30 (30.9)

Age, years

$32.0(19.0,51.2)$

$32.0(19.0,48.0)$

$31.0(19.0,53.0)$

Classification

Mild

67 (34.2)

36 (36.4)

31 (32.0)

Moderate

69 (35.2)

33 (33.3)

$36(37.1)$

Severe

$60(30.6)$

$30(30.3)$

$30(30.9)$

\section{Laboratory Investigation}

CD3 $+\mathrm{T}$ cell $\%$

CD3 + CD $4+T$ cell\%

$\mathrm{CD} 3+\mathrm{CD} 8+\mathrm{T}$ cell $\%$

$\mathrm{CD} 4+/ \mathrm{CD} 8+\mathrm{T}$ cell ratio

CD19 + B cell\%

CD16+56+ NK cell\%

$\mathrm{CD} 3+\mathrm{CD} 4+\mathrm{CD} 8+\mathrm{T}$ cell\%

CD $3+\mathrm{T}$ cell count, $\times 10^{9} / \mathrm{L}$

$\mathrm{CD} 3+\mathrm{CD} 4+\mathrm{T}$ cell count, $\times 10^{9} / \mathrm{L}$

CD $3+\mathrm{CD} 8+\mathrm{T}$ cell count, $\times 10^{9} / \mathrm{L}$
$74.1(69.3,78.2)$

$40.6( \pm 6.89)$

$27.6(24.1,30.7)$

$1.48(1.21,1.77)$

$13.6(10.6,16.5)$

$10.2(6.93,15.0)$

$0.32(0.18,0.48)$

$1.44(1.18,1.73)$

$0.78(0.66,0.96)$

$0.54(0.42,0.70)$
$72.7(67.7,78.0)$

$39.6( \pm 6.0)$

$27.3(24.3,30.4)$

$1.47( \pm 0.35)$

$13.7( \pm 5.2)$

$11.3(7.8,17.0)$

$0.33(0.16,0.48)$

$1.35(1.15,1.71)$

$0.78(0.61,0.94)$

$0.54(0.42,0.70)$

$0.55(0.42,0.70)$

Data are expressed as $\mathrm{N}(\%)$ for sex, mean ( \pm standard deviation) for continuous variables with normal distribution, and median (interquartile range) for continuous variables with skewed distribution.

Abbreviation: ANC: absolute neutrophil count; ALC: absolute lymphocyte count; AMC: absolute monocyte count; CRP: C-reactive protein; L\%: lymphocyte count as a percentage of white blood cell count; $\mathrm{M} \%$ : monocyte count as a percentage of white blood cell count; $\mathrm{N} \%$ : neutrophil count as a percentage of white blood cell count; LDH: lactate dehydrogenase; NK: natural killer; WBC: white blood cell count. 


\begin{tabular}{|c|c|c|c|}
\hline & $\begin{array}{l}\text { All Patients }(\mathrm{N}= \\
\text { 196) }\end{array}$ & $\begin{array}{l}\text { Training Cohort }(\mathrm{N} \\
=99)\end{array}$ & $\begin{array}{l}\text { Validation Cohort (N } \\
=97 \text { ) }\end{array}$ \\
\hline $\begin{array}{l}\mathrm{CD} 3+\mathrm{CD} 4+\mathrm{CD} 8+\mathrm{T} \text { cell count, } \\
\times 10^{9} / \mathrm{L}\end{array}$ & $0.01(0.00,0.01)$ & $0.01(0.00,0.01)$ & $0.01(0.00,0.01)$ \\
\hline CD19 + B cell count, $\times 10^{9} / \mathrm{L}$ & $0.25(0.18,0.37)$ & $0.25(0.17,0.37)$ & $0.26(0.20,0.34)$ \\
\hline $\begin{array}{l}\text { CD16+56+ NK cell count, } \\
\times 10^{9} / \mathrm{L}\end{array}$ & $0.19(0.14,0.30)$ & $0.21(0.15,0.32)$ & $0.18(0.12,0.25)$ \\
\hline $\mathrm{N} \%$ & $55.7( \pm 10.1)$ & $56.8( \pm 9.6)$ & $54.6( \pm 10.6)$ \\
\hline$L \%$ & $35.0(28.8,40.2)$ & $33.5(28.2,39.5)$ & $35.6(29.5,41.4)$ \\
\hline $\mathrm{M} \%$ & $6.25(5.18,7.30)$ & $6.20(5.15,7.30)$ & $6.40(5.20,7.30)$ \\
\hline WBC, $\times 10^{9} / \mathrm{L}$ & $5.60(4.77,6.70)$ & $5.60(4.85,6.80)$ & $5.40(4.50,6.70)$ \\
\hline ANC, $\times 10^{9} / \mathrm{L}$ & $3.13(2.35,3.82)$ & $3.20(2.63,3.88)$ & $3.05(2.26,3.77)$ \\
\hline ALC, $\times 10^{9} / \mathrm{L}$ & $1.89(1.57,2.36)$ & $1.90(1.60,2.35)$ & $1.82(1.56,2.36)$ \\
\hline AMC, $\times 10^{9} / \mathrm{L}$ & $0.35(0.28,0.44)$ & $0.35(0.29,0.44)$ & $0.34(0.28,0.42)$ \\
\hline Platelet, $\times 10^{9} / \mathrm{L}$ & $227(190,268)$ & $231( \pm 57.7)$ & $227(192,269)$ \\
\hline Albumin, $g / L$ & $41.7(39.7,43.3)$ & $42.2( \pm 3.3)$ & $41.2(39.3,42.5)$ \\
\hline $\mathrm{LDH}, \mathrm{U} / \mathrm{L}$ & $145(131,166)$ & $148(130,166)$ & $144(131,166)$ \\
\hline CRP, mg/L & $0.40(0.20,0.90)$ & $0.50(0.25,1.10)$ & $0.30(0.20,0.80)$ \\
\hline \multicolumn{4}{|c|}{$\begin{array}{l}\text { Data are expressed as } \mathrm{N}(\%) \text { for sex, mean ( } \pm \text { standard deviation) for continuous variables with } \\
\text { normal distribution, and median (interquartile range) for continuous variables with skewed } \\
\text { distribution. }\end{array}$} \\
\hline \multicolumn{4}{|c|}{$\begin{array}{l}\text { Abbreviation: ANC: absolute neutrophil count; ALC: absolute lymphocyte count; AMC: absolute } \\
\text { monocyte count; CRP: C-reactive protein; L\%: lymphocyte count as a percentage of white blood cell } \\
\text { count; M\%: monocyte count as a percentage of white blood cell count; N\%: neutrophil count as a } \\
\text { percentage of white blood cell count; LDH: lactate dehydrogenase; NK: natural killer; WBC: white blood } \\
\text { cell count. }\end{array}$} \\
\hline
\end{tabular}

\section{Association between disease severity and laboratory parameters}

In the training cohort, logistic analysis was used to compare the differences in clinical characteristics and laboratory parameters of patients between the non-severe disease group $(n=69)$ and the severe disease group $(\mathrm{n}=30)$. A univariate logistic regression model showed that the CD3 $+\mathrm{CD} 4+\mathrm{T}$ cell\% $(P=0.033)$, CD3 + CD $8+$ T cell\% $(P=0.007), \mathrm{CD} 4+/ \mathrm{CD} 8+\mathrm{T}$ cell ratio $(P<0.001$; Fig. $1 \mathrm{~A}), \mathrm{M} \%(P=0.037$; Fig. $1 \mathrm{~B})$ and 
albumin level ( $P=0.037$; Fig. $1 \mathrm{C})$ were five factors associated with disease severity, while the groups showed no differences in age, sex, and other laboratory parameters (Table 2). 
Table 2

Univariate logistic regression analysis of MDD severity in the training cohort

Non-severe $(\mathrm{N}=69) \quad$ Severe $(\mathrm{N}=30)$

P-value

Gender

0.370

Female

$37(53.6)$

$19(63.3)$

Male

$32(46.4)$

$11(36.7)$

Age, years

$32.0(18.0,48.0)$

$27.5(19.0,40.2)$

0.706

$\mathrm{CD} 3+\mathrm{T}$ cell\%

$72.0(67.7,76.7)$

$74.2(69.4,79.3)$

0.226

$\mathrm{CD} 3+\mathrm{CD} 4+\mathrm{T}$ cell $\%$

$40.4( \pm 6.13)$

$37.6( \pm 5.37)$

0.033

$\mathrm{CD} 3+\mathrm{CD} 8+\mathrm{T}$ cell $\%$

$26.3(22.9,29.8)$

$29.5(26.6,32.0) \quad 0.007$

CD4+/CD8 + T cell ratio

$1.55( \pm 0.37)$

$1.28( \pm 0.23)$

$<0.001$

CD19 + B cell\%

$13.8( \pm 5.09)$

$13.5( \pm 5.55)$

0.763

CD16 + 56 + NK cell\%

$12.1(7.75,17.3)$

$11.0(7.75,14.0)$

0.392

$\mathrm{CD} 3+\mathrm{CD} 4+\mathrm{CD} 8+\mathrm{T}$ cell $\%$

$0.34(0.17,0.54)$

$0.29(0.17,0.44)$

0.392

$\mathrm{CD} 3+\mathrm{T}$ cell count, $\times 10^{9} / \mathrm{L}$

$1.40(1.15,1.70)$

$1.33(1.19,1.71)$

0.673

$\mathrm{CD} 3+\mathrm{CD} 4+\mathrm{T}$ cell count, $\times 10^{9} / \mathrm{L}$

$0.81(0.66,0.94)$

$0.72(0.59,0.87)$

0.092

$\mathrm{CD} 3+\mathrm{CD} 8+\mathrm{T}$ cell count, $\times 10^{9} / \mathrm{L}$

$0.53(0.42,0.71)$

$0.54(0.44,0.70)$

0.661

$\mathrm{CD} 3+\mathrm{CD} 4+\mathrm{CD} 8+\mathrm{T}$ cell count, $\times 10^{9} / \mathrm{L}$

$0.01(0.00,0.01)$

$0.01(0.00,0.01)$

0.659

CD19 + B cell count, $\times 10^{9} / L$

$0.26(0.18,0.37)$

$0.24(0.16,0.39)$

0.642

CD16 + 56 + NK cell count, $\times 10^{9} / \mathrm{L}$

$0.22(0.16,0.36)$

$0.19(0.15,0.25)$

0.154

N\%

$57.4( \pm 9.79)$

$55.3( \pm 9.24)$

0.309

$\mathrm{L} \%$

$32.8(28.0,39.5)$

$36.1(29.1,40.6)$

0.398

$\mathrm{M} \%$

$5.90(5.00,6.90)$

$6.65(5.65,7.75)$

0.037

WBC, $\times 10^{9} / \mathrm{L}$

$5.60(5.10,6.90)$

$5.30(4.70,6.45)$

0.151

ANC, $\times 10^{9} / \mathrm{L}$

$3.33(2.83,3.96)$

$2.83(2.23,3.70)$

0.053

Abbreviation: ANC: absolute neutrophil count; ALC: absolute lymphocyte count; AMC: absolute monocyte count; CRP: C-reactive protein; L\%: lymphocyte count as a percentage of white blood cell count; $\mathrm{M} \%$ : monocyte count as a percentage of white blood cell count; $\mathrm{N} \%$ : neutrophil count as a percentage of white blood cell count; LDH: lactate dehydrogenase; NK: natural killer; WBC: white blood cell count. 


\begin{tabular}{|c|c|c|c|}
\hline & Non-severe $(\mathrm{N}=69)$ & Severe $(N=30)$ & $P$ value \\
\hline ALC, $\times 10^{9} / \mathrm{L}$ & $1.90(1.60,2.40)$ & $1.80(1.52,2.28)$ & 0.537 \\
\hline AMC, $\times 10^{9} / \mathrm{L}$ & $0.36(0.29,0.43)$ & $0.35(0.29,0.49)$ & 0.525 \\
\hline Platelet, $\times 10^{9} / \mathrm{L}$ & $226( \pm 52.2)$ & $243( \pm 68.3)$ & 0.180 \\
\hline Albumin, g/L & $42.7( \pm 3.38)$ & $41.2( \pm 2.93)$ & 0.037 \\
\hline $\mathrm{LDH}, \mathrm{U} / \mathrm{L}$ & $147(132,164)$ & $148(130,166)$ & 0.849 \\
\hline CRP, mg/L & $0.60(0.30,1.10)$ & $0.35(0.23,0.60)$ & 0.309 \\
\hline \multicolumn{4}{|c|}{$\begin{array}{l}\text { Abbreviation: ANC: absolute neutrophil count; ALC: absolute lymphocyte count; AMC: absolute } \\
\text { monocyte count; CRP: C-reactive protein; L\%: lymphocyte count as a percentage of white blood cell } \\
\text { count; M\%: monocyte count as a percentage of white blood cell count; N\%: neutrophil count as a } \\
\text { percentage of white blood cell count; LDH: lactate dehydrogenase; NK: natural killer; WBC: white blood } \\
\text { cell count. }\end{array}$} \\
\hline
\end{tabular}

The multivariate logistic regression model showed that the mean CD4+/CD8 + T cell ratio of the nonsevere disease group was significantly higher than that of the severe disease group (1.55 vs. 1.28; OR $0.019 ; 95 \% \mathrm{Cl}: 0.003-0.140 ; P<0.001)$; the mean albumin level of the non-severe disease group was significantly higher than that of the severe disease group (42.7 vs. $41.2 \mathrm{~g} / \mathrm{L}$; OR 0.839 ; $95 \mathrm{Cl}$ : 0.708-0.994; $P=0.043$ ); and the median $\mathrm{M} \%$ of the non-severe disease group was significantly lower than that severe disease group (5.90 vs. 6.65 ; OR 1.686; $95 \% \mathrm{Cl}$ : 1.139-2.494; $P=0.009$; Table 3).

Table 3

Multivariate logistic regression analysis of MDD severity in the training cohort

\begin{tabular}{|llll|}
\hline & B-coefficient & OR (95\% Cl) & P-value \\
\hline CD4+/CD8 + T cell ratio & -3.959 & $0.019(0.003,0.140)$ & $<0.001$ \\
\hline Albumin & -0.175 & $0.839(0.708,0.994)$ & 0.043 \\
\hline M\% & 0.522 & $1.686(1.139,2.494)$ & 0.009 \\
\hline Abbreviation: M\%: monocyte count as a percentage of white blood cell count. \\
\hline
\end{tabular}

On the basis of the three independent significant factors, namely,CD4+/CD8 + T cell ratio, albumin level and $\mathrm{M} \%$, a novel joint index was constructed through binary logistic regression analysis. The formula of the joint index was as follows:

Joint index $=-3.959 \times \mathrm{CD} 4+/ \mathrm{CD} 8+\mathrm{T}$ cell ratio $-0.175 \times$ albumin $+0.522 \times \mathrm{M} \%+8.739$

The logistic regression model showed that the mean joint index in the non-severe disease group was significantly lower than in the severe disease group (-1.71 [ \pm 1.52$]$ vs. $0.01[ \pm 0.96] ; P<0.001 ;$ Fig. $1 \mathrm{D})$. The 
ROC curves suggested that the best cut-off value of the joint index was - 1.2, indicating that patients with joint index values higher than -1.2 should be diagnosed as showing severe MDD, while those with index values less than -1.2 should be diagnosed as showing mild or moderate MDD. The AUC of the joint index was 0.850 (95\% Cl: $0.774-0.925)$, and the sensitivity and specificity were $90.9 \%$ and $70.0 \%$ respectively (Fig. 2A). Meanwhile, the best cut-off values of the $C D 4+/ C D 8+T$ cell ratio, albumin concentration and $\mathrm{M} \%$ were $1.5,40.6$ and 5.3 respectively. The AUC values of the CD4+/CD $8+T$ cell ratio, albumin level and M\% were 0.740 (95\%Cl: $0.643-0.837), 0.615$ (95\% Cl: $0.496-0.734)$ and 0.632 (95\%Cl: $0.516-0.749)$ respectively (Fig. 2B-D), which were all significantly lower than that of the joint index (all $P<0.05$; Table 4).

Table 4

Comparison of discriminative performance between the joint index and single factor in the training cohort

\begin{tabular}{|llllll|}
\hline & $\begin{array}{l}\text { Best cut-off } \\
\text { value }\end{array}$ & AUC (95\% Cl) & $\begin{array}{l}\text { Sensitivity } \\
(\%)\end{array}$ & $\begin{array}{l}\text { Specificity } \\
(\%)\end{array}$ & P-value \\
\hline Joint index & -1.2 & $\begin{array}{l}0.850(0.774- \\
0.925)\end{array}$ & 90.0 & 70.0 & Reference \\
\hline $\begin{array}{l}\text { CD4+/CD8+T cell } \\
\text { ratio }\end{array}$ & 1.5 & $\begin{array}{l}0.740(0.643- \\
0.837)\end{array}$ & 86.7 & 63.8 & 0.015 \\
\hline M\% & 5.3 & $\begin{array}{l}0.632(0.516- \\
0.749)\end{array}$ & 86.7 & 34.8 & $<0.001$ \\
\hline Albumin & 40.6 & $\begin{array}{l}0.615(0.496- \\
0.734)\end{array}$ & 46.7 & 79.7 & $<0.001$ \\
\hline
\end{tabular}

Abbreviation: M\%: monocyte count as a percentage of white blood cell count.

\section{Discriminative performance of the joint index in the validation cohort}

From January 1, 2021 to April 30, 2021, 97 MDD patients were enrolled as a validation cohort of which 31,36 and 30 patients were classified as showing mild moderate and severe MDD, respectively. The other detailed clinical characteristics and laboratory investigation of patients in this cohort are shown in Table 1.

In the validation cohort, the AUC of the joint index was 0.750 (95Cl: $0.645-0.849)$, and the sensitivity and the specificity were $86.7 \%$ and $62.7 \%$ respectively (Fig. $3 \mathrm{~A}$ ). Moreover, the median joint index value of the non-severe disease group was also significantly lower than that of severe disease group (-1.76 [IQR $3.29,-0.46]$ vs. 0.03 [IQR $-0.73,1.43]$; $P<0.001$; Fig. 3B).

\section{Discussion}

In this study, we identified the CD4+/CD8 + T cell ratio, albumin level and $M \%$ as three laboratory parameters significantly associated with the severity of MDD. On the basis of these three factors, we 
constructed a novel joint index that showed a good performance in discriminating disease severity, and we validated our findings in the validation cohort.

MDD is a prominent public health concern worldwide and approximately $6 \%$ of adults experience MDD per year [30]. Moreover, patients with MDD show an increased risk of the occurrence of several comorbidities, including diabetes mellitus and cardiovascular and cerebrovascular diseases, which further increase the disease burden [31]. MDD can also lead to death by suicide. Thus, early diagnosis and accurate classification of MDD can help clinicians design appropriate treatment strategies for patients and reduce the disease burden and death. In clinical practice, biomarkers from laboratory examinations are more sensitive and objective, which would facilitable accurate classification of the severity of MDD.

In the present study, we found that the $\mathrm{CD} 4+/ \mathrm{CD} 8+\mathrm{T}$ cell ratio and albumin concentration of patients with mild and moderate depressive disorder were significantly higher than those of patients with severe depressive disorder, while the $\mathrm{M} \%$ of patients with mild and moderate depressive disorder was significantly lower than that of patients with MDD. A number of studies have demonstrated that changes in immune function may play an important role in the disease process of depressive disorder. Dysregulation of the hypothalamic-pituitary adrenal axis is a hallmark of depressive disorder, which results in the hypersecretion of cortisol and exerts inhibitory effects on the immune system by suppressing the cellular immune response and increasing inflammatory cytokines [32]. A previous study investigated the specific alterations in the lymphocyte subsets of patients with MDD and found that the level of CD8 $+T$ cells in these patients was higher than that in the healthy control population [33]. In addition, another study showed that cortisol could increase the concentration of serum soluble CD8 or suppressor/cytotoxic antigen to suppress the immune response of patients with depressive disorder [34]. These results indicated that depressive disorder may damage the immune system and result in immunosuppression. The $\mathrm{CD} 4+/ \mathrm{CD} 8+\mathrm{T}$ cell ratio is an indicator of immune regulation. In this study, we found that the $C D 4+/ C D 8+T$ cell ratio of patients with severe depressive disorder was significantly lower, indicating a severe immune disorder.

Albumin, the most important protein in human plasma, is mainly produced by the liver, and it reflects the body's nutrition balance and helps maintain its osmotic pressure. Hypoalbuminemia has been reported in patients with mood disorders in several previous studies [35-37]. In addition, a diet-controlled study also demonstrated that the serum albumin level was significantly lower in patients with depressive disorders than in normal volunteers and that the reduced albumin level was related to the severity of the disease when rated by HAMD score, which was consistent with the results of this study [38]. Psychiatric illness may influence the serum concentrations of albumin by altering daily behaviors such as ingestion, thus, hypoalbuminemia in patients with depressive disorders may be due to dietary deficiencies. Serum albumin is a routinely tested factor from peripheral blood and can be considered as an easily available biomarker for accurate classification of the severity of depressive disorder. 
Monocytes originated from their progenitors in the bone marrow and are transported to the peripheral blood via the bloodstream. During the course of inflammation, circulating monocytes are recruited by series of chemokines and migrate into tissues, and then differentiated into macrophages or dendritic cells after conditioning by pro-inflammatory cytokines and microbial products. This process is essential for effective control of infection, and is involved in the pathogenesis of inflammatory and degenerative diseases [39]. A previous study found that the monocyte count and monocyte-to-lymphocyte ratio were significantly higher in patients with MDD than in healthy controls [40]. Similarly, another study found that patients with MDD exhibited significantly higher levels of serum pro-inflammatory IL-12 and IL-6, which were associated with increased numbers of circulating non-classical $C D 11 b^{+} C D 16^{\text {bright }} C D 14^{\text {neg }}$ monocytes and an increased activation state of classical $\mathrm{CD} 40^{+} \mathrm{CD} 86^{+}$monocytes [41]. These findings were also consistent with the results of the present study, which showed that the peripheral blood $\mathrm{M} \%$ was higher in patients with depressive disorder patients with severe disease, indicating the potential diagnostic value of monocyte counts.

Notably, a novel joint index based on the CD4+/CD8 + T cell ratio, albumin concentration and M\% was developed in the present study,and it showed superior sensitivity and specificity to discriminate the severity of depressive disorder in comparison to the individual significant factors. Moreover, the jont index score also showed good discriminative performance in the validation cohort. This novel joint index was based on objective biological markers from peripheral blood, which could facilitate a more easily and accurate severity classification of depressive disorder.

\section{Limitations}

This study had a few limitations. First, healthy control populations were lacking. Second, the sample size was relatively small, and a prospective study with a larger study population, was required to verify the efficacy of the joint index. Finally, this study focused on treatment-naïve patients, and did not analyze the association between variations in laboratory parameters after subsequent therapy and changes in the depressive disorder status.

\section{Conclusion}

In conclusion, we identified three laboratory parameters, namely CD4+/CD8 $+\mathrm{T}$ cell ratio, albumin concentration and $\mathrm{M} \%$, that were associated with the severity of depressive disorder, and constructed a novel joint index to discriminate disease severity more objectively and sensitively.

\section{Abbreviations}

MDD: Major depressive disorder; HAMD: Hamilton Depression Scale; MADRS: Montgomery-Asberg Depression Rating Scale ; CRP: C-reactive protein;TNF: tumor necrosis factor; DSM-5: diagnostic and statistical manual of mental disorders; WBC: white blood cell count; ANC: absolute neutrophil count; LDH: lactate dehydrogenase; EDTA: Ethylene Diamine Tetraacetic Acid; SD: standard deviation; IQR: 
interquartile ranges; OR: odds ratio ;Cl: confidence intervals; ROC: receiver operating characteristic; AUC: area under the curve

\section{Declarations}

\section{Acknowledgements}

The authors gratefully thank all patients for their kindness and willingness to be enrolled in this study.

\section{Author Contributions}

Wei CHEN, Jun ZHANG and Yuedi SHEN designed the study and reviewed the manuscript prior to submission. Dechun ZHOU coordinated the work and took the lead in drafting the manuscript and interpreting. Hongfeng YU, Hongfeng YAO and Lei HUANG carried out data collection. Shijin YUAN and Yan XIA performed the statistical analysis.

The corresponding author attests that all listed authors met authorship criteria and that no others meeting the criteria have been omitted. All authors have read and approved the final manuscript and, therefore, have full access to all the data in the study and take responsibility for the integrity and security of the data.

\section{Funding}

This research was supported grant from by Zhejiang Province TCM Modernization Special Project (2020ZX012), and the National Key Research \& Development Program of China (2017YFC1310502, 2016YFC1307205) to Wei Chen. the Key Research \& Development Program of Zhejiang Province (2018C03023) to Yuedi Shen.

\section{Availability of data and materials}

The datasets generated and analyzed during the current study are available from the corresponding author on reasonable request.

\section{Ethics approval and consent to participate}

The study was approved by the Institutional Ethics Committee of Sir Run Run Shaw Hospital, Hangzhou, China (No. Scientific Research 20191203-13), and all participants gave their written informed consents.

\section{Consent for publication}

Not applicable.

\section{Competing interests}


Regarding research work described in the paper, each one of our co-authors, Dechun Zhou, Hongfeng Yu, Hongfeng Yao, Shijin Yuan, Yan Xia, Lei Huang, Yuedi Shen, Jun Zhang, Wei Chen, has declared that there is no conflict of interest, has conformed to the Helsinki Declaration concerning human rights and informed consent, and has followed correct procedures concerning treatment of humans in research.

\section{References}

1. Kunugi $\mathrm{H}$, Hori $\mathrm{H}$, Ogawa S. Biochemical markers subtyping major depressive disorder. Psychiatry Clin Neurosci. 2015;69(10):597-608. https://10.1111/pcn.12299

2. Phillips ML, Chase HW, Sheline YI, Etkin A, Almeida JR, Deckersbach T, et al. Identifying predictors, moderators, and mediators of antidepressant response in major depressive disorder: neuroimaging approaches. Am J Psychiatry. 2015;172(2):124-38. https://10.1176/appi.ajp.2014.14010076

3. Smith K. Mental health: a world of depression. Nature. 2014;515(7526):181. https://10.1038/515180a

4. Penninx BW, Milaneschi Y, Lamers F, Vogelzangs $N$. Understanding the somatic consequences of depression: biological mechanisms and the role of depression symptom profile. BMC Med. 2013;11:129. https://10.1186/1741-7015-11-129

5. Otte C, Gold SM, Penninx BW, Pariante CM, Etkin A, Fava M, et al. Major depressive disorder. Nat Rev Dis Primers. 2016;2:16065. https://10.1038/nrdp.2016.65

6. Beurel E, Toups M, Nemeroff CB. The Bidirectional Relationship of Depression and Inflammation: Double Trouble. Neuron. 2020;107(2):234-56. https://10.1016/j.neuron.2020.06.002

7. Anthes E. Depression: a change of mind. Nature. 2014;515(7526):185-7. https://10.1038/515185a

8. McGirr A, Renaud J, Seguin M, Alda M, Turecki G. Course of major depressive disorder and suicide outcome: a psychological autopsy study. J Clin Psychiatry. 2008;69(6):966-70. https://10.4088/jcp.v69n0612

9. Kalin NH. Insights Into Suicide and Depression. Am J Psychiatry. 2020;177(10):877-80. https://10.1176/appi.ajp.2020.20081207

10. Hamilton M. A rating scale for depression. J Neurol Neurosurg Psychiatry. 1960;23:56-62. https://10.1136/jnnp.23.1.56

11. Montgomery SA, Asberg M. A new depression scale designed to be sensitive to change. $\mathrm{Br} \mathrm{J}$ Psychiatry. 1979;134:382-9. https://10.1192/bjp.134.4.382

12. Bagby RM, Ryder AG, Schuller DR, Marshall MB. The Hamilton Depression Rating Scale: has the gold standard become a lead weight? Am J Psychiatry. 2004;161(12):2163-77. https://10.1176/appi.ajp.161.12.2163

13. Muller MJ, Himmerich $H$, Kienzle B, Szegedi A. Differentiating moderate and severe depression using the Montgomery-Asberg depression rating scale (MADRS). J Affect Disord. 2003;77(3):255-60. https://10.1016/s0165-0327(02)00120-9 
14. Carneiro AM, Fernandes F, Moreno RA. Hamilton depression rating scale and montgomery-asberg depression rating scale in depressed and bipolar I patients: psychometric properties in a Brazilian sample. Health Qual Life Outcomes. 2015;13:42. https://10.1186/s12955-015-0235-3

15. Dichter GS, Gibbs D, Smoski MJ. A systematic review of relations between resting-state functionalMRI and treatment response in major depressive disorder. J Affect Disord. 2015;172:8-17. https://10.1016/j.jad.2014.09.028

16. Diener C, Kuehner C, Brusniak W, Ubl B, Wessa M, Flor H. A meta-analysis of neurofunctional imaging studies of emotion and cognition in major depression. Neuroimage. 2012;61(3):677-85. https://10.1016/j.neuroimage.2012.04.005

17. Hamilton JP, Etkin A, Furman DJ, Lemus MG, Johnson RF, Gotlib IH. Functional neuroimaging of major depressive disorder: a meta-analysis and new integration of base line activation and neural response data. Am J Psychiatry. 2012;169(7):693-703. https://10.1176/appi.ajp.2012.11071105

18. Sheline YI, Barch DM, Donnelly JM, Ollinger JM, Snyder AZ, Mintun MA. Increased amygdala response to masked emotional faces in depressed subjects resolves with antidepressant treatment: an fMRI study. Biol Psychiatry. 2001;50(9):651-8. https://10.1016/s0006-3223(01)01263-x

19. Jokela M, Virtanen M, Batty GD, Kivimaki M. Inflammation and Specific Symptoms of Depression. JAMA Psychiatry. 2016;73(1):87-8. https://10.1001/jamapsychiatry.2015.1977

20. Kohler O, Krogh J, Mors O, Benros ME. Inflammation in Depression and the Potential for AntiInflammatory Treatment. Curr Neuropharmacol. 2016;14(7):732-42. https://10.2174/1570159x14666151208113700

21. Cai L, Xu L, Wei L, Chen W. Relationship of Mean Platelet Volume To MDD: A Retrospective Study. Shanghai Arch Psychiatry. 2017;29(1):21-9. https://10.11919/j.issn.1002-0829.216082

22. Dowlati Y, Herrmann N, Swardfager W, Liu H, Sham L, Reim EK, et al. A meta-analysis of cytokines in major depression. Biol Psychiatry. 2010;67(5):446-57. https://10.1016/j.biopsych.2009.09.033

23. Howren MB, Lamkin DM, Suls J. Associations of depression with C-reactive protein, IL-1, and IL-6: a meta-analysis. Psychosom Med. 2009;71(2):171-86. https://10.1097/PSY.0b013e3181907c1b

24. Khandaker GM, Pearson RM, Zammit S, Lewis G, Jones PB. Association of serum interleukin 6 and Creactive protein in childhood with depression and psychosis in young adult life: a population-based longitudinal study. JAMA Psychiatry. 2014;71(10):1121-8.

https://10.1001/jamapsychiatry.2014.1332

25. Wium-Andersen MK, Orsted DD, Nielsen SF, Nordestgaard BG. Elevated C-reactive protein levels, psychological distress, and depression in 73, 131 individuals. JAMA Psychiatry. 2013;70(2):176-84. https://10.1001/2013.jamapsychiatry.102

26. Jeon YW, Han SI, Park EJ. The relation between immunologic variables and symptom factors in patients with major depressive disorder. Ann Gen Psychiatry. 2018;17:32. https://10.1186/s12991018-0201-7

27. Wu W, Zheng YL, Tian LP, Lai JB, Hu CC, Zhang P, et al. Circulating T lymphocyte subsets, cytokines, and immune checkpoint inhibitors in patients with bipolar II or major depression: a preliminary study. 
Sci Rep. 2017;7:40530. https://10.1038/srep40530

28. Shen YD, Lu PL, Wei LL, Cai LQ, Hu XY, Chen W. Fluoxetine treatment for major depression decreases the plasma levels of cytokines. . Afr J Biotechnol. 2010;9(43):7346-51.

29. American Psychiatric Association. Diagnostic and statistical manual of mental disorders, fifth edition: Diagnostic and statistical manual of mental disorders.; 2013.

30. Bromet E, Andrade LH, Hwang I, Sampson NA, Alonso J, de Girolamo G, et al. Cross-national epidemiology of DSM-IV major depressive episode. BMC Med. 2011;9:90. https://10.1186/17417015-9-90

31. Hare DL, Toukhsati SR, Johansson P, Jaarsma T. Depression and cardiovascular disease: a clinical review. Eur Heart J. 2014;35(21):1365-72. https://10.1093/eurheartj/eht462

32. Irwin MR, Miller AH. Depressive disorders and immunity: 20 years of progress and discovery. Brain Behav Immun. 2007;21(4):374-83. https://10.1016/j.bbi.2007.01.010

33. Suzuki H, Savitz J, Kent Teague T, Gandhapudi SK, Tan C, Misaki M, et al. Altered populations of natural killer cells, cytotoxic $T$ lymphocytes, and regulatory $T$ cells in major depressive disorder: Association with sleep disturbance. Brain Behav Immun. 2017;66:193-200. https://10.1016/j.bbi.2017.06.011

34. Maes M, Vandoolaeghe E, Ranjan R, Bosmans E, Van Gastel A, Bergmans R, et al. Increased serum soluble CD8 or suppressor/cytotoxic antigen concentrations in depression: suppressive effects of glucocorticoids. Biol Psychiatry. 1996;40(12):1273-81. https://10.1016/0006-3223(95)00627-3

35. Maes M, Wauters A, Neels H, Scharpe S, Van Gastel A, D'Hondt P, et al. Total serum protein and serum protein fractions in depression: relationships to depressive symptoms and glucocorticoid activity. J Affect Disord. 1995;34(1):61-9. https://10.1016/0165-0327(94)00106-j

36. Maes M, Vandoolaeghe E, Neels H, Demedts P, Wauters A, Meltzer HY, et al. Lower serum zinc in major depression is a sensitive marker of treatment resistance and of the immune/inflammatory response in that illness. Biol Psychiatry. 1997;42(5):349-58. https://10.1016/S0006-3223(96)00365-4

37. Swartz CM. Albumin decrement in depression and cholesterol decrement in mania. J Affect Disord. 1990;19(3):173-6. https://10.1016/0165-0327(90)90088-p

38. Huang SY, Chiu CC, Shen WW, Chang HC, Wu PL, Su KP. Hypoalbuminemia in drug-free patients with major depressive disorder compared with a dietary matched control group: a clinical meaning beyond malnutrition. Eur Neuropsychopharmacol. 2005;15(2):227-30. https://10.1016/j.euroneuro.2004.10.003

39. Shi C, Pamer EG. Monocyte recruitment during infection and inflammation. Nat Rev Immunol. 2011;11(11):762-74. https://10.1038/nri3070

40. Zhou L, Ma X, Wang W. Inflammation and Coronary Heart Disease Risk in Patients with Depression in China Mainland: A Cross-Sectional Study. Neuropsychiatr Dis Treat. 2020;16:81-6. https://10.2147/NDT.S216389

41. Nowak W, Grendas LN, Sanmarco LM, Estecho IG, Arena AR, Eberhardt N, et al. Pro-inflammatory monocyte profile in patients with major depressive disorder and suicide behaviour and how ketamine 
induces anti-inflammatory M2 macrophages by NMDAR and mTOR. EBioMedicine. 2019;50:290-305. https://10.1016/j.ebiom.2019.10.063

\section{Figures}

(A)

$\square$ Non-severe disease group $\square$ Severe disease group

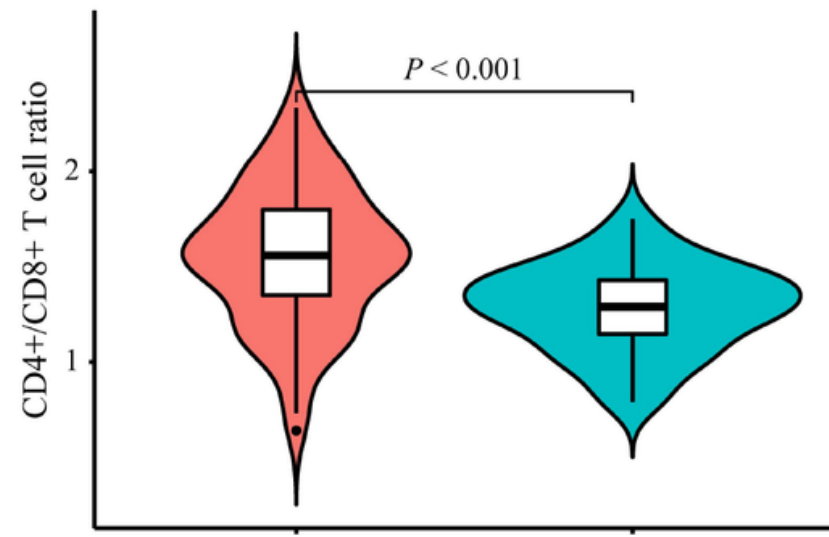

Non-severe disease group Severe disease group

(C)

Non-severe disease group $\square$ Severe disease group



Non-severe disease group Severe disease group
(B)



Non-severe disease group Severe disease group

(D)

Non-severe disease group $\square$ Severe disease group

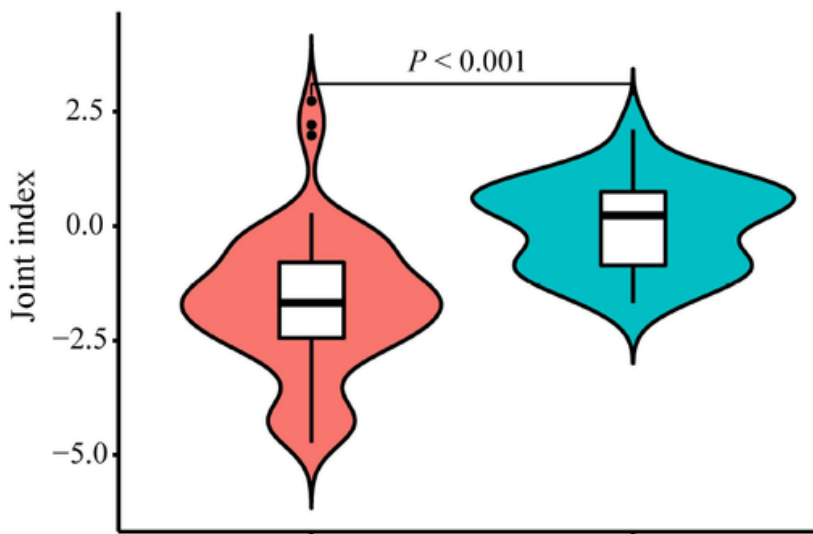

Non-severe disease group Severe disease group

\section{Figure 1}

Violin plot for comparing the laboratory parameters between two groups in the training cohort $(A)$ The mean $\mathrm{CD} 4+/ \mathrm{CD} 8+\mathrm{T}$ cell ratio in the non-severe disease group was significantly higher than that in the severe disease group $(\mathrm{P}<0.001)$; $(\mathrm{B})$ the median $\mathrm{M} \%$ in the non-severe disease group was significantly lower than that in the severe disease group $(P=0.037)$; $(C)$ the mean albumin concentration in the nonsevere disease group was significantly higher than that in the severe disease group ( $P=0.037)$; (D) the 
mean joint index in the non-severe disease group was significantly lower than that in the severe disease group $(\mathrm{P}<0.001)$.

(A)

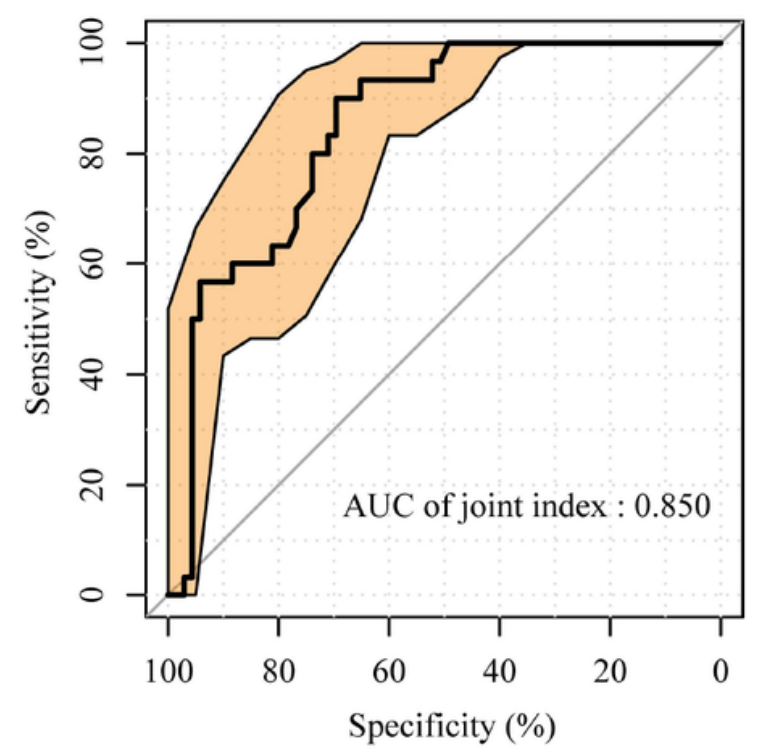

(C)

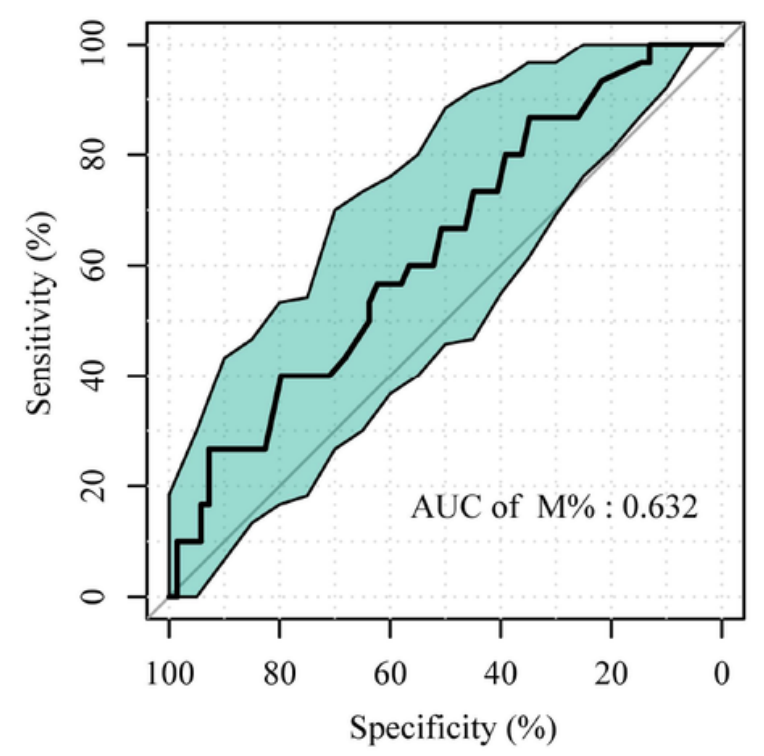

(B)



(D)

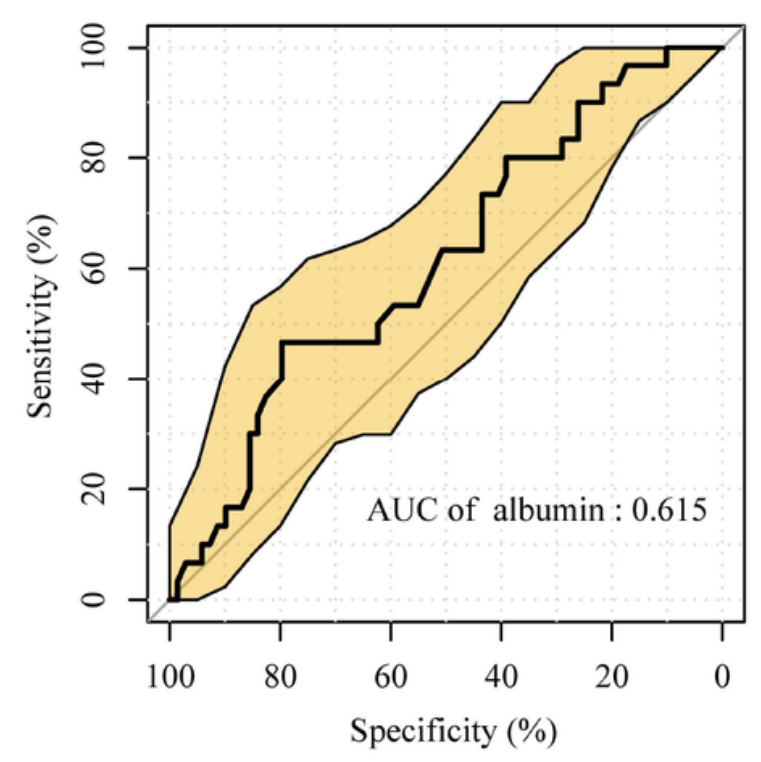

Figure 2

ROC curves of the joint index and laboratory parameters to discriminate the disease severity in the training cohort (A) The AUC of the joint index is 0.850 (95Cl: 0.774-0925); (B) the AUC of the CD4+/CD8+ T cell ratio is 0.740 ( $95 \% \mathrm{Cl}: 0.643-0.837)$; (C) the AUC of $\mathrm{M} \%$ is 0.632 (95Cl: $0.516-0.749)$; (D) the AUC of albumin concentration is 0.615 (95\% Cl: $0.496-0.734)$. 
(A)

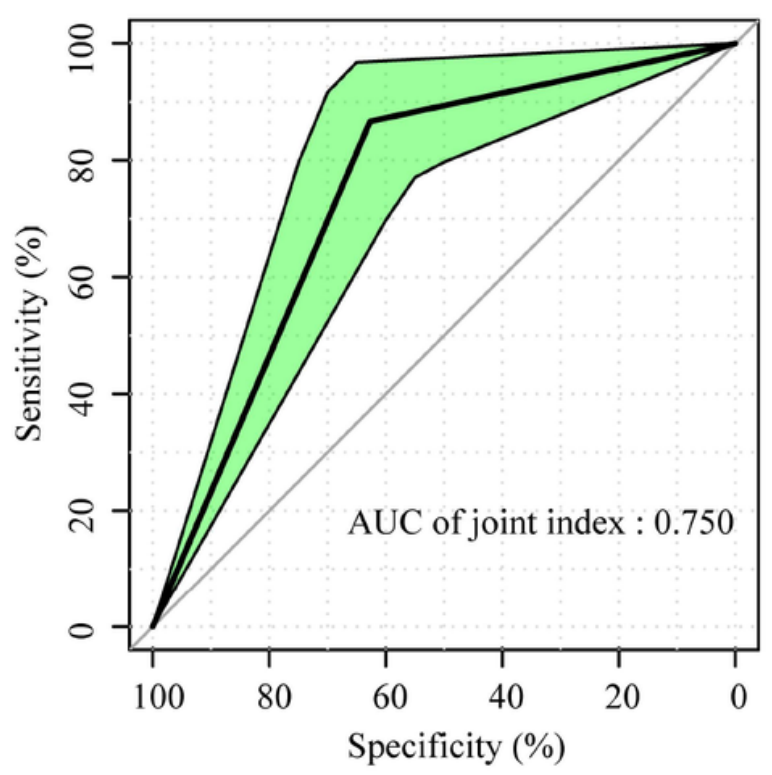

(B)

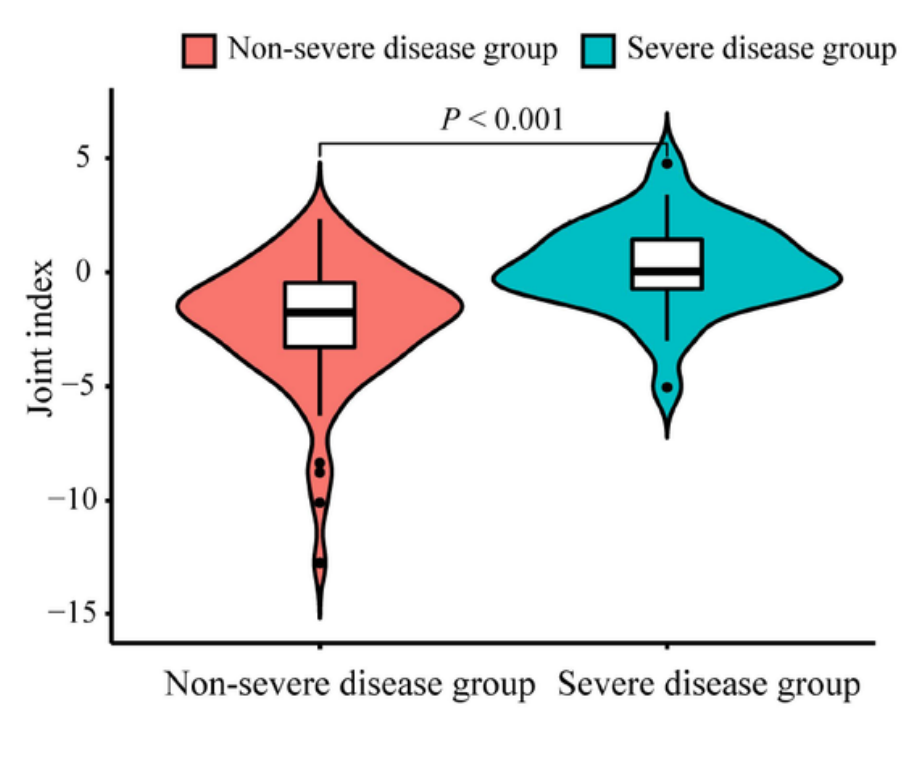

\section{Figure 3}

ROC curves and violin plot of the joint index to discriminate disease severity in validation cohort (A) The AUC of the joint index is 0.750 (95\% Cl: $0.645-0.849)$; (B) the median joint index in the non-severe disease group was also significantly lower than in the severe disease group $(P<0.001)$. 